foreseeable future must continue to rely on medical preeminence in these areas. Moreover, many patients' needs, such as emotional support, may not be consciously formulated as wants. And providing a service more responsive to patients' demands clearly has considerable implications for resources.

Ironically, just as a consumerist perspective begins to develop there has been an increase in consultations initiated by the doctor (such as those for health promotion), in which doctors' definitions of need take precedence over patients' overt wants. Some surveys suggest that patients do not mind this approach, ${ }^{13}$ but more detailed work suggests many qualifications to this apparent mandate for medicine once again to take the initiative in defining need. ${ }^{1+}$

Reflecting on the doctor-patient relationship over 50 years ago, Cassidy suggested that the only thing that doctors wanted to hear from their patients was "an account of their symptoms, as concise as possible and chronological."'15 This view stands in complete opposition to what patients report as what they most value: a doctor who listens ${ }^{16}$-if only to begin to appreciate what the patient wants. And though it would seem that listening is a medical skill more valued than previously, this does not necessarily mean that doctors have yet learnt always to hear what patients are saying.

Reader in Sociology as Applied to Medicine,

DAVID ARMSTRONG

United Medical and Dental Schools of Guy's and St Thomas's Hospitals,

London SE1 9RT

Brackenbury HB. Patient and doctor. London: Hodder and Stoughton, 1935

Armstrong D. The patient's view. Soc Sci Med 1984;18:737-44.

Mechanic D. The concept of illness behaviour. Fournal of Chronic Diseases 1962:15:189-94.

4 Ley P. Towards better doctor-patient communications. In: Bennett AE, ed. Communcation between doctors and patients. Oxford: Oxford University Press, 1976:75-98.

5 Cartwright A. Human relations and hospital care. London: Routledge and Kegan Paul, 1962

6 Gregory J. Patients' attitudes to the hospital service. London: HMSO, 1978.

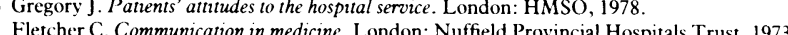

8 Salmon P, Quine J. Patients intentions in primary care: measurement and preliminary investigation. Psychology and Health $1989 \cdot 3: 103-10$.
.

9 Tuckett D, Boulton M, Olson C, Williams A. Meetings berween experts: an approach to sharing idea in medical consultations. London: Tavistock, 1985 .

10 Kleinman A, Eisenberg L, Good B. Culture, illness and cure. Ann Intern Med 1978;88:251-9.

11 Miller SM, Brody DS, Summerton J. Styles of coping with threat: implications for health. F Pers Soc Psychol 1988;54:142-8.

12 Martin E, Russell D, Goodwin S, Chapman R, North M, Sheridan M. Why patients consult and what happens when they do. BMJ 1991;303:289-92.

13 Wallace P, Brennan PJ, Haines A. Are general practitioners doing enough to promote healthy lifestyle? BMJ 1987;294:940-2.

14 Stott NCH, Pill RM. Advise yes, dictate no. Patients' views on health promotion in the consultation. Fam Pract 1990; 7:125-31

15 Cassidy $M$. Doctor and patient. Lancet 1938;i:175-9.

16 Smith C, Armstrong D. Comparisons of criteria derived by governments for evaluating general practitioner services. BMF 1989;299:494-6.

\title{
Total knee replacement
}

\section{Getting better all the time}

With operations for knee arthroplasty increasing faster than those for total hip replacement some of the British scepticism about knee surgery is clearly disappearing. Recent studies justify this change of attitude: in experienced units the insertion of condylar prostheses in well selected cases probably has a higher success rate than that for total hip replacement and gives rise to fewer long term complications and failures. ${ }^{12}$

The operation's success depends on the selection of patients, choice of prosthesis, and surgical skill. Patients should be judged on their symptoms rather than their radiological signs; the correlation between the two may be poor. Provided they are fit enough for surgery patients with pain at rest and disturbed sleep should be offered operation. Those whose pain on movement confines them to their home and garden should also be considered. The operation relieves pain in more than $95 \%$ of cases, ${ }^{23}$ with functional improvement occurring in over $90 \% .^{3+}$ Patients with rheumatoid arthritis do particularly well. ${ }^{3}$

Some doctors would exclude anyone under 60 from the operation, but that could mean confining young adults to wheelchairs for years until they had "earned" their operation. Failure rates for mostly now obsolete designs have exceeded $20 \%$ at 10 years, ${ }^{5}$ but the original total condylar knee replacement has a survivorship a little in excess of $90 \%$ at 15 years, a reassuring prospect for the 35 year old rheumatoid patient, confined to a wheel chair. The posterior stabilised derivative of the total condylar replacement has a $97 \%$ survivorship at 10 years. Thus for the younger patient the possibility of subsequent failure and need for revision is probably less than it is for hip replacement.

Deciding whether to operate on the active, usually overweight, and often male patient with an osteoarthritic knee is more difficult. Claims of "absolute agony" after a spirited descent of Snowdon should be taken circumspectly, especially if proposals for losing weight, physiotherapy, and buying a walking stick are regarded with disdain. Such patients need to know that although surgery produces excellent results knee arthroplasties are most vulnerable in those who wish to dance or walk up or ski down mountains. These patients have to understand the consequences of fractures and dislocations (both very rare), late infection, and, above all, wear and loosening.

As with other major operations complications may occur at the time of surgery. Technical problems such as neurovascular disorders and perioperative fractures should be avoidable. Rarely infection and thromboembolism (despite prophylaxis) occur, with disastrous results.

What prosthesis should be used? Few knees, however deformed or unstable, cannot be successfully replaced with a prosthesis with a total condylar type of resurfacing. ${ }^{14}$ This has superseded prostheses depending on hinges,${ }^{68}$ long stems in medullary cavities,,${ }^{7.9}$ small stress bearing areas, ${ }^{10}$ and major sacrifices of bone stock. ${ }^{8}$ These should no longer be routinely used: not only are complications and survival of the joint worse but surgical options are limited if further operations are needed. ${ }^{6}$ Unfortunately, some orthopaedic surgeons continue to use them, justifying the doubts that some people hold about the operation.

Lastly, there is the question of surgical skill. With increasing subspecialisation in orthopaedics the time for occasional knee replacements performed in non-specialist units may soon be over.

JONATHAN NOBLE Consultant Orthopaedic Surgeon ROY C HILTON

Hope Hospital,

Salford M6 8HD

1 Insall JN. Total knee replacement. In: Insall JN, ed. Surgery of the knee. New York: Churchill

Livingstone, 1984:587-695.
2 Ranawat CS, Boachie-Adjei O. Survivorship analysis and results of total condylar knee arthroplasty; 8-11 year follow-up period. Clin Orthop 1988;226:6-13.
and

3 Noble J, Hodgkinson JP, Brabu KJ, Potts H. The total condylar knee replacement: a robust and Noble J, Hodgkinson JP, Brabu KJ, Potts $\mathrm{H}$. The total condylar knee replacement: a robust and
reliable prosthesis. In: Noble J, Galasko CSB, eds. Recent developments in orthopaedic surgery. Manchester: Manchester University Press, 1987:274-82.

4 Vince KG, Insall JN, Kelly MA. The total condylar prosthesis. 10-12 year results of the cemented knee replacement. F Bone foint Surg [Br] 1989;71:793-7.

5 Scuderi GR, Insall JN, Windsor RE, Moran MC. Survivorship of cemented knee replacements. f Bone foint Surg [Br] 1989;71:798-803.

6 Noble J. Total knee replacement - not a bridge too far. F Bone foint Surg [Br] 1990;72:173-4.

7 Stulberg SD. Arthrodesis in failed total knee replacements. Orthop Clin North Am 1982;13:213-24. 8 Simison AJM, Noble J, Hardings K. Complications of the Attenborough knee replacement. $\mathcal{F}$ Bon foint Surg [Br] 1986;68: 100-4.

Tew $M$, Waugh W, Forster IW. Comparing the results of different types of knee replacement. J Bone foint Surg $[\mathrm{Br}]$ 1985;67:775-9.

10 Barlin CE, Jankin I. A 5-8 year follow up of the Sheehan total knee arthroplasty. $f$ Bone foint Surg $[B r]$ 1987;69:680. 